$11-1-2013$

\title{
Case-Control Studies with Jointly Misclassified Exposure and Confounding Variables
}

Tze-San Lee

Western Illinois University, Macomb, IL, leetzesan@gmail.com

Follow this and additional works at: http://digitalcommons.wayne.edu/jmasm

Part of the Applied Statistics Commons, Social and Behavioral Sciences Commons, and the Statistical Theory Commons

\section{Recommended Citation}

Lee, Tze-San (2013) "Case-Control Studies with Jointly Misclassified Exposure and Confounding Variables," Journal of Modern Applied Statistical Methods: Vol. 12 : Iss. 2 , Article 11.

DOI: $10.22237 /$ jmasm/1383279000

Available at: http://digitalcommons.wayne.edu/jmasm/vol12/iss2/11

This Regular Article is brought to you for free and open access by the Open Access Journals at DigitalCommons@WayneState. It has been accepted for inclusion in Journal of Modern Applied Statistical Methods by an authorized editor of DigitalCommons@WayneState. 


\section{Case-Control Studies with Jointly Misclassified Exposure and Confounding Variables}

Tze-San Lee

Western Illinois University

Macomb, IL

The issue of $2 \times 2 \times 2$ case-control studies is addressed when both exposure and confounding variables are jointly misclassified. Two scenarios are considered: the classification errors of exposure and confounding variables are independent or not independent. The bias-adjusted cell probability estimates which account for the misclassification bias are presented. The effect of misclassification on the measure of crude odds ratio either unstratified or stratified by the confounder, Mantel-Haenszel summary odds ratio, the confounding component in the crude odds ratio, the first and second order multiplicative interaction are assessed through the sensitivity analysis from using the data on the asthma deaths of 5-45 aged patients in New Zealand.

Keywords: $\quad$ Asthma mortality, confounding, effect modification, Mantel-Haenszel summary odds ratio, multiplicative interaction.

\section{Introduction}

Misclassification is a ubiquitous problem in epidemiologic studies. A $2 \times 2$ casecontrol study with a single exposure variable being misclassified has been thoroughly studied (Fleiss et al. 2003, Chapter 17; Gustafson 2004, Chapter 5; Kleinbaum et al. 1982, Chapter 12; Rothman et al 2008, Chapter 19). In contrast, the misclassification of a confounding factor has attracted less attention, although there are some important papers on this topic (Ahlbom \& Steineck 1992; Axelson 1978; Greenland 1980; Greenland \& Robins 1985; Kupper 1984; Savitz \& Baron 1989; Walker 1985). However, few papers address the issue when the study (or exposure) factor and the confounding factor are simultaneously misclassified. Most articles focused merely on the aspect that the confounding factor is misclassified.

Tze-San Lee is presently working as a mathematical statistician at the Centers for Disease Control and Prevention in Chamblee, GA. Email at tjl3@cdc.gov. 
Although Fung \& Howe (1984) considered the joint misclassification of polytomous exposure and confounding variables, they do not provide the biasadjusted estimator for the cell probability. Tzonou et al. (1986) investigates the effect of misclassification on the summary odds ratio in case-control studies in which both exposure and confounding variables are jointly misclassified. But they merely consider the scenario that the classification errors of the exposure and confounding factors are independent. Again, no bias-adjusted estimators are provided in their paper.

The scenarios are addressed here in which the joint classification errors of the exposure and confounding factors are either independent or not independent. Below, necessary background materials are first reviewed. The misclassification probabilities are then defined. The formulas for all bias-adjusted measures of the effect caused by the joint misclassification of exposure and confounder are thus presented. A real-world data set is used as an example to illustrate how to calculate the misclassification probabilities by employing the counterfactual (or correctly classified) tables when the validation data are not available. A sensitivity analysis is then carried out for the admissible counterfactual tables.

\section{Methodology \& Background}

Let $D, E$, and $C$ be three dichotomous variables, in which $D$ denotes the subject's outcome (disease) variable ( $=1$ if present, 0 otherwise), $E$ the subject's exposure variable (= 1 if exposed, 0 otherwise), and $C$ (= 1 if present, 0 otherwise) the extraneous (a suspected confounding) variable. Assume that a simple random sampling scheme is used to collect the data of size $n$ which are then cross-classified into table 1 in which $E^{*}$ and $C^{*}$ are imperfect classification variables for $E$ and $C$.

Table 1: Observed contingency table of three dichotomous variables $D \times E \times C$

\begin{tabular}{lllll}
\hline & & $\boldsymbol{C}^{*}=\mathbf{1}$ & $\boldsymbol{C}^{*}=\mathbf{0}$ & Total \\
\hline $\boldsymbol{D}=\mathbf{1}$ & $E^{*}=1$ & $n_{111}$ & $n_{110}$ & $n_{11+}$ \\
Cases) & $E^{*}=0$ & $n_{101}$ & $n_{100}$ & $n_{10+}$ \\
& Total & $\boldsymbol{n}_{1+1}$ & $\boldsymbol{n}_{1+0}$ & $\boldsymbol{n}_{1++}$ \\
\hline \multirow{2}{*}{$\mathbf{0}$} & $E^{*}=1$ & $n_{011}$ & $n_{010}$ & $n_{01+}$ \\
(Controls) & $E^{*}=0$ & $n_{001}$ & $n_{000}$ & $n_{00+}$ \\
& Total & $\mathbf{n}_{0+1}$ & $\mathbf{n}_{0+0}$ & $\mathbf{n}_{0++}$ \\
\hline
\end{tabular}




\section{TZE-SAN LEE}

The crude cell probability estimators are given by: for fixed i

$$
\hat{p}_{i j k}=n_{i j k} / n_{(i)}
$$

where $n_{(i)} \equiv n_{i++}=n_{i 11}+n_{i 10}+n_{i 01}+n_{i 00}$, the “+” sign in the subscript represents summation in the usual way.

It is assumed that Eq. 1 follows a multinomial distribution with parameters $\mathrm{n}_{(\mathrm{i})}$ and $p_{i j k}$. For fixed $\mathrm{i}$, the variance-covariance matrix of $\left\{\hat{p}_{i j k}\right\}$ is given by

$$
\Sigma_{(i)}=\left[\sigma_{j k(i)}\right]_{j, k=1}^{4}=n_{(i)} \cdot\left[\begin{array}{cccc}
p_{i 11} \cdot q_{i 11} & -p_{i 11} \cdot p_{i 10} & -p_{i 11} \cdot p_{i 01} & -p_{i 11} \cdot p_{i 00} \\
\sigma_{12(i)} & p_{i 10} \cdot q_{i 10} & -p_{i 10} \cdot p_{i 01} & -p_{i 10} \cdot p_{i 00} \\
\sigma_{13(i)} & \sigma_{23(i)} & p_{i 01} \cdot q_{i 01} & -p_{i 01} \cdot p_{i 00} \\
\sigma_{14(i)} & \sigma_{24(i)} & \sigma_{34(i)} & p_{i 00} \cdot q_{i 00}
\end{array}\right]
$$

To measure the effect of the exposure $E$ and the extraneous $C$, calculate respectively from Table 1 the following estimates for the exposure odds ratios of $E$ unstratified and stratified by $C$ :

$$
\begin{gathered}
\hat{R}_{E}=\left(n_{11+} \cdot n_{00+}\right) /\left(n_{10+} \cdot n_{01+}\right) \\
\hat{R}_{E \mid C=1}=\left(n_{111} \cdot n_{001}\right) /\left(n_{101} \cdot n_{011}\right)
\end{gathered}
$$

and

$$
\hat{R}_{E \mid C=0}=\left(n_{110} \cdot n_{000}\right) /\left(n_{100} \cdot n_{010}\right)
$$

In addition, the Mantel-Haenszel summary odds ratio is given by (Mantel and Haenszel 1959)

$$
\hat{R}_{E \mid M H}=\left(n_{111} \cdot n_{001} \cdot n_{++1}^{-1}+n_{110} \cdot n_{000} \cdot n_{++0}^{-1}\right) \cdot\left(n_{101} \cdot n_{011} \cdot n_{++1}^{-1}+n_{100} \cdot n_{010} \cdot n_{++0}^{-1}\right)^{-1}
$$

Now let the ratios of odds ratios (Eqs. 3-6) be defined respectively by

$$
\hat{\phi}_{E \mid C}=\hat{R}_{E \mid M H} / \hat{R}_{E}
$$

and 


$$
\hat{\phi}_{h m g}=\hat{R}_{E \mid C=1} / \hat{R}_{E \mid C=0}
$$

where "hmg" in the subscript of Eq. 8 denote the word "homogeneous". If the estimated value of $\hat{\phi}_{E \mid C}$ is greater or less than $10 \%$ of the null value of unity, the extraneous variable $C$ is said to be a confounder. However, this condition is only sufficient, but not necessary as other conditions will be given in the section of Discussion. Two strata are said to be heterogeneous if the estimated value of $\hat{\phi}_{h m g}$ is significantly different from the null value of unity; otherwise, it is said to be homogeneous.

Let $R_{1^{s t} O I(i)}$ and $R_{2^{n d} \text { OI }}$ denote respectively the $1^{\text {st }}$ and $2^{\text {nd }}$ order (multiplicative) interaction between $E$ and $C$ and among $D, E$ and $C$ (Lee 2012). Then the estimates of these ratios are given respectively as follows:

$$
\hat{R}_{1^{t} \text { OI }(i)}=\left(n_{i 11} \cdot n_{i 00}\right) /\left(n_{i 10} \cdot n_{i 01}\right)
$$

and

$$
\hat{R}_{2^{n d} \text { OI }}=\left(n_{111} \cdot n_{010} \cdot n_{100} \cdot n_{010}\right) /\left(n_{101} \cdot n_{011} \cdot n_{110} \cdot n_{000}\right)
$$

Two variables $E$ and $C$ are said to be have a first order multiplicative interaction if the estimated value of Eq. 9 is significantly different from the null value of unity; otherwise, there does not exist multiplicative interaction between $E$ and $C$. Three variables $D, E$ and $C$ are said to be have a second-order multiplicative interaction if the estimated value of Eq. 10 is significantly different from the null value of unity; otherwise, there does not exist second-order multiplicative interaction among $D, E$ and $C$. The extraneous variable $C$ is said to be an effect modifier if either the estimated value of Eqs. 8 or 10 are significantly different from the null value of unity; otherwise, $C$ is not an effect modifier. By the way, it is easy to show that Eq. 8 equals Eq. 10.

In addition, let $R_{C}$ denote a measure of the strength of confounding by the extraneous variable $C$ (Miettinen 1972),

$$
\hat{R}_{C}=\left(n_{110} \cdot n_{101} \cdot n_{100}^{-1}+n_{010} \cdot n_{001} \cdot n_{000}^{-1}\right) \cdot n_{00+} /\left(n_{10+} \cdot n_{01+}\right)
$$




\section{TZE-SAN LEE}

$E$ and $C$ are jointly misclassified

Suppose that $D$ is not misclassified at all, but only $E$ and $C$ are jointly misclassified. There are two scenarios between $E$ and $C$ which have to be considered separately.

Scenario I: The classification errors of $E$ and $C$ are independent.

For this scenario, each cell misclassification probability is obtained as the product of the corresponding two row/column marginal misclassification probabilities. The false positive and false negative probabilities for $Y=E$ or $C$ are defined as follows:

$$
\gamma_{Y(i)}=\operatorname{Pr}\left(Y^{*}=0 \mid Y=1 ; D=i\right) \text { and } \delta_{Y(i)}=\operatorname{Pr}\left(Y^{*}=1 \mid Y=0 ; D=i\right)
$$

For $i=1,0$, let

$$
\begin{aligned}
& p_{(i)}=\left[p_{i 11}, p_{i 10}, p_{i 01}, p_{i 00}\right]^{T} \\
& \hat{p}_{(i)}=\left[\hat{p}_{i 11}, \hat{p}_{i 10}, \hat{p}_{i 01}, \hat{p}_{i 00}\right]^{T}
\end{aligned}
$$

Thus, by using Eq. 12, for $i=1,0$

$$
E\left(\hat{p}_{(i)}\right)=W_{I(i)} p_{(i)}
$$

where the misclassification matrix $W_{I(i)}$ is given by (Barron 1977; Tzonou et al. 1986)

$$
\begin{aligned}
W_{I(i)} & =\left[w_{I(i j k)}\right] \\
& \equiv\left[\begin{array}{cccc}
\left(1-\gamma_{E(i)}\right)\left(1-\gamma_{C(i)}\right) & \left(1-\gamma_{E(i)}\right) \delta_{C(i)} & \left(1-\gamma_{C(i)}\right) \delta_{E(i)} & \delta_{E(i)} \delta_{C(i)} \\
\left(1-\gamma_{E(i)}\right) \gamma_{C(i)} & \left(1-\gamma_{E(i)}\right)\left(1-\delta_{C(i)}\right) & \delta_{E(i)} \gamma_{C(i)} & \delta_{E(i)}\left(1-\delta_{C(i)}\right) \\
\gamma_{E(i)}\left(1-\gamma_{C(i)}\right) & \gamma_{E(i)} \delta_{C(i)} & \left(1-\delta_{E(i)}\right)\left(1-\gamma_{C(i)}\right) & \left(1-\delta_{E(i)}\right) \delta_{C(i)} \\
\gamma_{E(i)} \gamma_{C(i)} & \gamma_{E(i)}\left(1-\delta_{C(i)}\right) & \left(1-\delta_{E(i)}\right) \gamma_{C(i)} & \left(1-\delta_{E(i)}\right)\left(1-\delta_{C(i)}\right)
\end{array}\right]
\end{aligned}
$$

By conditioning on that $\gamma_{Y(i)}$ and $\delta_{Y(i)}$ for $Y=E$ or $C$ are known, the vector of bias-adjusted cell probability estimator (BACP) $\breve{p}_{I(i)}\left(=\left[\breve{p}_{i 11(I)}, \breve{p}_{i 10(I)}, \breve{p}_{i 01(I)}, \breve{p}_{i 00(I)}\right]^{T}\right)$ is then defined by 


$$
\breve{p}_{I(i)}=W_{I(i)}^{-1} \hat{p}_{(i)}=V_{I(i)} \hat{p}_{(i)}
$$

where the inverse $V_{\mathrm{I}(\mathrm{i})}$ of $W_{\mathrm{I}(\mathrm{i})}$ is given by

$$
\begin{aligned}
V_{I(i)} \equiv W_{I(i)}^{-1} & =\Delta_{I(i)}^{-\frac{1}{2}} \cdot\left[\begin{array}{cccc}
\left(1-\delta_{E(i)}\right)\left(1-\delta_{C(i)}\right) & -\gamma_{C(i)}\left(1-\delta_{E(i)}\right) & -\gamma_{E(i)}\left(1-\delta_{C(i)}\right) & \gamma_{E(i)} \gamma_{C(i)} \\
-\delta_{C(i)}\left(1-\delta_{E(i)}\right) & \left(1-\gamma_{C(i)}\right)\left(1-\delta_{E(i)}\right) & \gamma_{E(i)} \delta_{C(i)} & -\gamma_{E(i)}\left(1-\gamma_{C(i)}\right) \\
-\delta_{E(i)}\left(1-\delta_{C(i)}\right) & \delta_{E(i)} \gamma_{C(i)} & \left(1-\gamma_{E(i)}\right)\left(1-\delta_{C(i)}\right) & -\gamma_{C(i)}\left(1-\gamma_{E(i)}\right) \\
\delta_{E(i)} \delta_{C(i)} & -\delta_{E(i)}\left(1-\gamma_{C(i)}\right) & -\delta_{C(i)}\left(1-\gamma_{E(i)}\right) & \left(1-\gamma_{E(i)}\right)\left(1-\gamma_{C(i)}\right)
\end{array}\right]
\end{aligned}
$$

where $\Delta_{I(i)} \equiv \operatorname{det}\left(W_{I(i)}\right)=\left[\left(1-\gamma_{E(i)}-\delta_{E(i)}\right)\left(1-\gamma_{C(i)}-\delta_{C(i)}\right)\right]^{2}$.

In order for $W$ to be invertible, the following constraints on its false positive and false negative rates for both exposure and confounding variables are imposed:

$$
\gamma_{E(i)}+\delta_{E(i)}<1 \text { and } \gamma_{C(i)}+\delta_{C(i)}<1
$$

Scenario II: The classification errors of $E$ and $C$ are not independent.

For this scenario, there are 16 possibly cross-classified conditional probabilities of $E^{*}$ and $C^{*}$ as follows: for fixed $j^{\prime}, k^{\prime}, i, k=1,0$

$$
\lambda_{j^{\prime} k^{\prime}(i)}^{j k}=\operatorname{Pr}\left(E^{*}=j, C^{*}=k \mid E=j^{\prime}, C=k^{\prime} ; D=i\right)
$$

where $\left\{\lambda_{j^{\prime} k^{\prime}(i)}^{j k}\right\}$, for $j^{\prime}, k^{\prime}=1,0$, are required to satisfy the following identities:

$$
\sum_{j, k=0}^{1} \lambda_{j^{\prime} k^{\prime}(i)}^{j k}=1,0 \leq \lambda_{j^{\prime} k^{\prime}(i)}^{j k} \leq 1
$$

Among the $\left\{\lambda_{j^{\prime} k^{\prime}(i)}^{j k}\right\}$, four are correctly classified and 12 are misclassification probabilities. Because the misclassification can go equally from one cell to another three cells, it is appropriate to assume that they all equal to one another, that is, $\quad \theta_{1(i)} \equiv \lambda_{11(i)}^{10}=\lambda_{11(i)}^{01}=\lambda_{11(i)}^{00} \quad, \quad \theta_{2(i)} \equiv \lambda_{10(i)}^{11}=\lambda_{10(i)}^{01}=\lambda_{10(i)}^{00} \quad$, 


\section{TZE-SAN LEE}

$\theta_{3(i)} \equiv \lambda_{01(i)}^{11}=\lambda_{01(i)}^{10}=\lambda_{01(i)}^{00} \quad, \quad$ and $\quad \theta_{4(i)} \equiv \lambda_{00(i)}^{11}=\lambda_{00(i)}^{10}=\lambda_{00(i)}^{01} \quad . \quad$ Thus, the misclassification matrix is given by

$$
W_{I I(i)}=\left[\begin{array}{cccc}
1-\theta_{2(i)}-\theta_{3(i)}-\theta_{4(i)} & \theta_{2(i)} & \theta_{3(i)} & \theta_{4(i)} \\
\theta_{1(i)} & 1-\theta_{1(i)}-\theta_{3(i)}-\theta_{4(i)} & \theta_{3(i)} & \theta_{4(i)} \\
\theta_{1(i)} & \theta_{2(i)} & 1-\theta_{1(i)}-\theta_{2(i)}-\theta_{4(i)} & \theta_{4(i)} \\
\theta_{1(i)} & \theta_{2(i)} & \theta_{3(i)} & 1-\theta_{1(i)}-\theta_{2(i)}-\theta_{3(i)}
\end{array}\right]
$$

In addition, the inverse matrix $V_{\mathrm{II}(\mathrm{i})}$ of $W_{\mathrm{II}(\mathrm{i})}$ is given by

$$
\begin{aligned}
V_{I I(i)} \equiv W_{I I(i)}^{-1} & \\
& =\Delta_{I I(i)}^{-\frac{1}{3}}\left[\begin{array}{cccc}
1-\theta_{1(i)}-2 \theta_{2(i)} & -\theta_{1(i)} & -\theta_{1(i)} & -\theta_{1(i)} \\
-\theta_{2(i)} & 1-\theta_{2(i)}-2 \theta_{4(i)} & -\theta_{2(i)} & -\theta_{2(i)} \\
-\theta_{3(i)} & -\theta_{3(i)} & 1-2 \theta_{1(i)}-\theta_{3(i)} & -\theta_{3(i)} \\
-\theta_{4(i)} & -\theta_{4(i)} & -\theta_{4(i)} & 1-2 \theta_{3(i)}-\theta_{4(i)}
\end{array}\right]
\end{aligned}
$$

where $\Delta_{I I(i)}=\operatorname{det}\left(W_{I I(i)}\right)=\left(1-\theta_{1(i)}-\theta_{2(i)}-\theta_{3(i)}-\theta_{4(i)}\right)^{3}$. For this scenario, the BACP estimator is given by

$$
\breve{p}_{I I(i)}=W_{I I(i)}^{-1} \hat{p}_{(i)}=V_{I I(i)} \hat{p}_{(i)}
$$

The misclassification probabilities $\left(\left(\gamma_{Y}, \delta_{Y}\right)\right.$ or $\left.\left(\theta_{1(i)}, \theta_{2(i)}, \theta_{3(i)}, \theta_{4(i)}\right)\right)$ are said to be feasible if the misclassification matrix $\left(W_{\mathrm{I}(\mathrm{i})}\right.$ or $\left.W_{\mathrm{II}(\mathrm{i})}\right)$ is nonsingular, or equivalently, its determinant is nonzero. The BACP estimator (Eqs. 16 or 23) is said to be admissible if every component of its vector is nonnegative and their sum equals to the total probability one. In theory, it is possible to find the admissibility constraints which are required to be imposed on the misclassification probability. Yet, because it does not yield inequalities as neat as that of case-control studies with a single exposure variable (Lee 2009), it is therefore omitted here. Nevertheless, the admissibility constraints can be checked in practical applications by taking a case-by-case approach as illustrated by the example in the next section. 


\section{JOINTLY MISCLASSIFIED EXPOSURE \& CONFOUNDING VARIABLES}

From Eq. 16, for $j, k=1,0$

$$
\breve{n}_{i j k} \equiv n_{(i)} \cdot \breve{p}_{i j k}
$$

By substituting Eqs. 16 or 23 into Eqs. 3-11, obtain the corresponding bias-

adjusted estimates $\breve{R}_{E}, \breve{R}_{E \mid C=1}, \breve{R}_{E \mid C=0}, \breve{R}_{E \mid M H}, \breve{\phi}_{E}, \breve{\phi}_{I}, \breve{R}_{1^{t} \text { OII }(i)}, \breve{R}_{2^{n d} \text { OI }}$, and $\breve{R}_{C}$. Note that the crude estimators are merely a special case of the lower end of the biasadjusted one when its false positive and false negative rates are all zero.

\section{Example}

The data in Table 2 are taken from Crane et al. (1989). A case-control study was conducted to examine the hypothesis that fenoterol by metered dose inhaler increases the risk of death in patients with asthma. Cases were drawn from the National Asthma Mortality Survey which identified all asthma deaths in New Zealand from August 1981 to July 1983. Of the 271 asthma deaths identified in the survey, 125 occurred in patients aged 5-45 years, and these formed the case group. For each case, 4 controls, matched for age and ethnic group, were selected from asthma admissions to hospitals to which the cases themselves would have been admitted, had they survived. Controls were obtained for 124 out of the 125 cases. 7 cases were subsequently excluded because they died after admission to hospitals. Therefore the analysis pertains to 117 cases and 468 matched controls.

In terms of symbols, the disease, exposure and extraneous variables are given as follows:

$$
\begin{aligned}
& D=\text { asthma death (= } 1 \text { if outpatient deaths, = } 0 \text { if hospitalized controls), } \\
& E=\text { use of prescribed fenoterol (= } 1 \text { if yes, }=0 \text { if no), } \\
& C=\text { use of corticosteroids (= } 1 \text { if used, = } 0 \text { if not used). }
\end{aligned}
$$

If the data are not misclassified, the crude estimators with its 95\% confidence interval $(C I)$ are obtained by using Eqs. 3-11 and A.1-A.15 in the appendix: $\hat{R}_{E}=1.55$ (95\% CI: $1.03-2.33$ ), $\hat{R}_{E \mid C=1}=6.45$ (95\% CI: $2.56-16.3$ ), $\hat{R}_{E \mid C=0}=0.96$ (95\% CI: $\left.0.59-1.55\right), \hat{R}_{E \mid M H}=1.53$ (95\% CI: $\left.1.24-1.87\right)$, $\hat{\phi}_{E \mid C}=0.98$ (95\% CI: $\left.0.62-1.55\right), \hat{\phi}_{h m g}=6.73$ (95\% CI: $\left.2.37 \quad-19.1\right)$, $\hat{R}_{1^{t} \text { OI }(1)}=5.46$ (95\% CI: $\left.2.13-14.0\right), \hat{R}_{1^{t} O I(0)}=0.81$ (95\% CI: $0.52-1.27$ ), $\hat{R}_{2^{n d} \text { OI }}=\hat{\phi}_{h m g}\left(95 \% C I\right.$ : same as $\left.\hat{\phi}_{h m g}\right)$, and $\hat{R}_{C}=1.34$ (95\% CI:1.03-2.33). 


\section{TZE-SAN LEE}

As was pointed out by O'Donnell et al (1989) who reviewed the data for the group allegedly at highest risk, some of 20 such fatal cases which were recorded by Crane et al might not use prescribed fenoterol as reported by the general practitioner. In 7 of the 18 cases, the beta-agonist in use immediately before death was not or might not have been fenoterol. Hence, the data used by Crane et al were likely to be misclassified.

Suppose that the data are misclassified. The proposed bias-adjusted estimator can be used, namely, replacing $n_{i j k}$ in Eqs. 3-11 by the values of Eq. 24 to account for the misclassification bias. However, before calculating $\breve{n}_{i j k}$ in Eq. 24, calculate the misclassification probabilities. Here, the idea of counterfactual thinking was employed in creating the correctly classified table to serve as a gold standard for calculating the misclassification probability (Epstude \& Roese 2008). Recall that the actually observed table is the only concrete source of information. Therefore, the observed table is taken as a factual one. Then, the correctly classified table is nothing but a counterfactual $(C F)$ table corresponding to the factual (observed misclassified) table. $C F$ tables are said to be feasible (or admissible) if the misclassification matrix associated with the calculated misclassification probabilities is nonsingular, namely, its determinant is nonzero (or if the bias-adjusted cell probability estimators (Eqs. 16 or 23) are admissible).

At first, the construction of $20 \mathrm{CF}$ tables was tried. However, only 8 counterfactual models for cases and controls were listed here. Even among these 8 models, only 2 models (models 4 and 5, boldface in Table 3a) for cases under scenario I were admissible. For all other models either the 3rd component of the BACP had a negative value ( $C F$ tables 1 and 8) or the sum of the all components of the BACP estimator did not equal one ( $C F$ tables 2-3 and 6-7) (Table 3a, column 5). Even worse, none under scenario II for cases were admissible, because either the 3rd component of the BACP estimator had a negative value ( $C F$ tables 1-2 and 7-8) or the sum of all four components of BACP estimator did not equal one ( $C F$ tables 3-6) (Table 3a, column 8). For controls, only CF tables 3-6 were admissible under either scenario I or II (boldface in Table 3b). 


\section{JOINTLY MISCLASSIFIED EXPOSURE \& CONFOUNDING VARIABLES}

Table 2: A case-control study for the asthma deaths in New Zealand

\begin{tabular}{lllll}
\hline$D=1$ & & $C^{*}=1$ & $C^{*}=0$ & Total \\
\hline (Cases) & $E^{*}=1$ & 26 & 34 & 60 \\
\hline & $E^{*}=0$ & 7 & 50 & 57 \\
\hline \multirow{3}{*}{$D=0$ (Controls) } & Total & 33 & 84 & 117 \\
\cline { 2 - 5 } & $E^{*}=1$ & 38 & 151 & 189 \\
\cline { 2 - 5 } & $E^{*}=0$ & 66 & 213 & 279 \\
\cline { 2 - 5 } & Total & $\mathbf{1 0 4}$ & $\mathbf{3 6 4}$ & $\mathbf{4 6 8}$ \\
\hline
\end{tabular}

Table 3: Counterfactual tables with its false positive and false negative rates, determinant of the misclassification matrix under two scenarios for

\section{(a) Cases}

\begin{tabular}{|c|c|c|c|c|c|c|c|}
\hline \multirow[b]{2}{*}{ CF table } & \multirow[b]{2}{*}{$\begin{array}{l}\left(\mathrm{n}_{111}, \mathrm{n}_{110}\right. \\
\left.\mathrm{n}_{101}, \mathrm{n}_{100}\right)\end{array}$} & \multicolumn{3}{|l|}{ Scenario I } & \multicolumn{3}{|l|}{ Scenario II } \\
\hline & & $\begin{array}{l}\left(\gamma_{E(1)}, \delta_{E(1)},\right. \\
\left.\gamma_{C(1)}, \delta_{C(1)}\right)\end{array}$ & $\Delta_{I(1)}$ & $\begin{array}{l}\left(\breve{p}_{I(111)}, \breve{p}_{I(110)}\right. \\
\left.\breve{p}_{I(101)}, \breve{p}_{I(100)}\right)\end{array}$ & $\begin{array}{l}\left(\theta_{1(1)}, \theta_{2(1)},\right. \\
\left.\theta_{3(1)}, \theta_{4(1)}\right)\end{array}$ & $\Delta_{I I(1)}$ & $\begin{array}{l}\left(\breve{p}_{I I(111)}, \breve{p}_{I(110)},\right. \\
\left.\breve{p}_{I I(101)}, \breve{p}_{I(100)}\right)\end{array}$ \\
\hline 1 & $\begin{array}{l}(30,38 \\
11,38)\end{array}$ & $\begin{array}{l}(0.06,0.08, \\
0.11,0.05)\end{array}$ & 0.53 & $\begin{array}{l}(0.23,0.28 \\
-0.005,0.46)\end{array}$ & $\begin{array}{l}(0.02,0.02, \\
0.07,0.05)\end{array}$ & 0.59 & $\begin{array}{l}(0.23,0.29 \\
-0.02,0.38)\end{array}$ \\
\hline 2 & $\begin{array}{l}(29,37, \\
10,41)\end{array}$ & $\begin{array}{l}(0.05,0.06, \\
0.08,0.04)\end{array}$ & 0.62 & $\begin{array}{l}(0.23,0.29 \\
0.01,0.45)\end{array}$ & $\begin{array}{l}(0.02,0.01, \\
0.06,0.03)\end{array}$ & 0.67 & $\begin{array}{l}(0.23,0.29 \\
-0.001,0.39)\end{array}$ \\
\hline 3 & $\begin{array}{l}(28,36, \\
9,44)\end{array}$ & $\begin{array}{l}(0.03,0.04, \\
0.06,0.02)\end{array}$ & 0.73 & $\begin{array}{l}(0.22,0.29 \\
0.03,0.44)\end{array}$ & $\begin{array}{l}(0.01,0.01, \\
0.04,0.02)\end{array}$ & 0.77 & $\begin{array}{l}(0.22,0.29 \\
0.02,0.40)\end{array}$ \\
\hline 4 & $\begin{array}{l}(27,35, \\
8,47)\end{array}$ & $\begin{array}{l}(0.02,0.02, \\
0.03,0.01)\end{array}$ & 0.86 & $\begin{array}{l}(0.22,0.29 \\
0.05,0.43)\end{array}$ & $\begin{array}{l}(0.006,0.005 \\
0.02,0.01)\end{array}$ & 0.87 & $\begin{array}{l}(0.224,0.293 \\
0.039,0.416)\end{array}$ \\
\hline 5 & $\begin{array}{l}(25,33 \\
6,53)\end{array}$ & $\begin{array}{l}(0.02,0.02, \\
0.03,0.01)\end{array}$ & 0.85 & $\begin{array}{l}(0.22,0.29 \\
0.04,0.43)\end{array}$ & $\begin{array}{l}(0.007,0.005 \\
0.03,0.01)\end{array}$ & 0.87 & $\begin{array}{l}(0.224,0.294 \\
0.035,0.415)\end{array}$ \\
\hline 6 & $\begin{array}{l}(24,32, \\
5,56)\end{array}$ & $\begin{array}{l}(0.03,0.03, \\
0.06,0.02)\end{array}$ & 0.72 & $\begin{array}{l}(0.22,0.29 \\
0.03,0.44)\end{array}$ & $\begin{array}{l}(0.01,0.01 \\
0.06,0.02)\end{array}$ & 0.73 & $\begin{array}{l}(0.23,0.30 \\
0.003,0.40)\end{array}$ \\
\hline 7 & $\begin{array}{l}(23,31 \\
4,59)\end{array}$ & $\begin{array}{l}(0.05,0.05 \\
0.10,0.03)\end{array}$ & 0.60 & $\begin{array}{l}(0.23,0.28 \\
0.006,0.45)\end{array}$ & $\begin{array}{l}(0.02,0.02 \\
0.09,0.03)\end{array}$ & 0.61 & $\begin{array}{l}(0.23,0.31 \\
-0.04,0.38)\end{array}$ \\
\hline 8 & $\begin{array}{l}(22,30, \\
3,62)\end{array}$ & $\begin{array}{l}(0.07,0.07, \\
0.14,0.05)\end{array}$ & 0.50 & $\begin{array}{l}(0.23,0.28 \\
-0.02,0.46)\end{array}$ & $\begin{array}{l}(0.03,0.02 \\
0.13,0.04)\end{array}$ & 0.48 & $\begin{array}{l}(0.24,0.32 \\
-0.10,0.35)\end{array}$ \\
\hline
\end{tabular}




\section{TZE-SAN LEE}

Table 3 Continued

\section{(b) Controls}

\begin{tabular}{|c|c|c|c|c|c|c|c|}
\hline \multirow[b]{2}{*}{ CF table } & \multirow[b]{2}{*}{$\begin{array}{l}\left(\mathrm{n}_{011}, \mathrm{n}_{010}\right. \\
\left.\mathrm{n}_{001}, \mathrm{n}_{000}\right)\end{array}$} & \multicolumn{3}{|l|}{ Scenario I } & \multicolumn{3}{|l|}{ Scenario II } \\
\hline & & $\begin{array}{l}\left(\gamma_{E(0)}, \delta_{E(0)},\right. \\
\left.\gamma_{C(0)}, \delta_{C(0)}\right)\end{array}$ & $\Delta_{I(0)}$ & $\begin{array}{l}\left(\breve{p}_{I(011)}, \breve{p}_{I(010)},\right. \\
\left.\breve{p}_{I_{(001)}}, \breve{p}_{I(000)}\right)\end{array}$ & $\begin{array}{l}\left(\theta_{1(0)}, \theta_{2(0)},\right. \\
\left.\theta_{3(0)}, \theta_{4(0)}\right)\end{array}$ & $\Delta_{I I(0)}$ & $\begin{array}{l}\left(\breve{p}_{I(011)}, \breve{p}_{I(010)},\right. \\
\left.\breve{p}_{I(001)}, \breve{p}_{I I(000)}\right)\end{array}$ \\
\hline 1 & $\begin{array}{l}(42,155 \\
70,201)\end{array}$ & $\begin{array}{l}(0.02,0.01 \\
0.04,0.01)\end{array}$ & 0.84 & $\begin{array}{l}(0.07,0.32 \\
0.13,0.46)\end{array}$ & $\begin{array}{l}(0.02,0.004 \\
0.01,0.01)\end{array}$ & 0.88 & $\begin{array}{l}(0.07,0.33 \\
0.13,0.45)\end{array}$ \\
\hline 2 & $\begin{array}{l}(41,154 \\
69,204)\end{array}$ & $\begin{array}{l}(0.02,0.01, \\
0.03,0.01)\end{array}$ & 0.88 & $\begin{array}{l}(0.07,0.32 \\
0.13,0.46)\end{array}$ & $\begin{array}{l}(0.01,0.003 \\
0.01,0.01)\end{array}$ & 0.91 & $\begin{array}{l}(0.07,0.32 \\
0.13,0.46)\end{array}$ \\
\hline 3 & $\begin{array}{l}(40,153 \\
68,207)\end{array}$ & $\begin{array}{l}(0.01,0.01, \\
0.02,0.01)\end{array}$ & 0.92 & $\begin{array}{l}(0.08,0.32 \\
0.14,0.46)\end{array}$ & $\begin{array}{l}(0.01,0.002 \\
0.005,0.005)\end{array}$ & 0.94 & $\begin{array}{l}(0.07,0.32 \\
0.14,0.46)\end{array}$ \\
\hline 4 & $\begin{array}{l}(39,152 \\
67,210)\end{array}$ & $\begin{array}{l}(0.005,0.004 \\
0.01,0.003)\end{array}$ & 0.96 & $\begin{array}{l}(0.08,0.32 \\
0.14,0.46)\end{array}$ & $\begin{array}{l}(0.004,0.001 \\
0.003,0.002)\end{array}$ & 0.97 & $\begin{array}{l}(0.08,0.32 \\
0.14,0.46)\end{array}$ \\
\hline 5 & $\begin{array}{l}(37,150 \\
65,216)\end{array}$ & $\begin{array}{l}(0.005,0.004 \\
0.01,0.003)\end{array}$ & 0.96 & $\begin{array}{l}(0.08,0.32 \\
0.14,0.46)\end{array}$ & $\begin{array}{l}(0.004,0.001 \\
0.003,0.002)\end{array}$ & 0.97 & $\begin{array}{l}(0.08,0.32 \\
0.14,0.46)\end{array}$ \\
\hline 6 & $\begin{array}{l}(36,149 \\
64,219)\end{array}$ & $\begin{array}{l}(0.01,0.007 \\
0.02,0.005)\end{array}$ & 0.92 & $\begin{array}{l}(0.08,0.32 \\
0.14,0.46)\end{array}$ & $\begin{array}{l}(0.01,0.002 \\
0.005,0.005)\end{array}$ & 0.94 & $\begin{array}{l}(0.07,0.32 \\
0.14,0.46)\end{array}$ \\
\hline 7 & $\begin{array}{l}(35,148 \\
63,222)\end{array}$ & $\begin{array}{l}(0.02,0.01, \\
0.03,0.01)\end{array}$ & 0.88 & $\begin{array}{l}(0.07,0.32 \\
0.13,0.46)\end{array}$ & $\begin{array}{l}(0.01,0.003 \\
0.01,0.001)\end{array}$ & 0.91 & $\begin{array}{l}(0.07,0.33 \\
0.13,0.46)\end{array}$ \\
\hline 8 & $\begin{array}{l}(34,147 \\
62,225)\end{array}$ & $\begin{array}{l}(0.02,0.01, \\
0.04,0.01)\end{array}$ & 0.84 & $\begin{array}{l}(0.07,0.32 \\
0.13,0.46)\end{array}$ & $\begin{array}{l}(0.02,0.004 \\
0.01,0.01)\end{array}$ & 0.88 & $\begin{array}{l}(0.06,0.33 \\
0.13,0.46)\end{array}$ \\
\hline
\end{tabular}

Table 4: Estimated values of bias-adjusted estimators for all statistics (Eqs. 3-11) with its $95 \% \mathrm{Cl}$ for selected admissible counterfactual tables

\begin{tabular}{|c|c|c|c|c|}
\hline \multirow[t]{2}{*}{ Test $(95 \% \mathrm{Cl})$} & \multicolumn{4}{|c|}{ CF table: (case ${ }_{l}$, control $)$} \\
\hline & $(\# 4, \# 3)$ & $(\# 4, \# 4)$ & $(\# 4, \# 5)$ & $(\# 4, \# 6)$ \\
\hline \multirow{2}{*}{$\breve{R}_{E}$} & 1.59 & 1.58 & 1.58 & 1.59 \\
\hline & $(1.22-2.06)$ & $(1.22-2.05)$ & $(1.22-2.06)$ & $(1.22-2.06)$ \\
\hline \multirow{2}{*}{$\bar{R}_{E \mid M H}$} & 1.554 & 1.551 & 1.551 & 1.554 \\
\hline & $(1.22-1.98)$ & $(1.22-1.97)$ & $(1.21-1.98)$ & $(1.22-1.97)$ \\
\hline \multirow{2}{*}{$\breve{R}_{E \mid C=1}$} & 8.72 & 8.62 & 8.63 & 8.72 \\
\hline & $(3.00-25.3)$ & $(2.98-25.0)$ & $(2.98-25.0)$ & $(2.99-25.4)$ \\
\hline \multirow{2}{*}{$\breve{R}_{E \mid C=0}$} & 0.94 & 0.94 & 0.94 & 0.94 \\
\hline & $(0.35-2.58)$ & $(0.35-2.57)$ & $(0.35-2.57)$ & $(0.35-2.58)$ \\
\hline
\end{tabular}


JOINTLY MISCLASSIFIED EXPOSURE \& CONFOUNDING VARIABLES

Table 4 Continued

\begin{tabular}{|c|c|c|c|c|}
\hline Test $(95 \% \mathrm{Cl})$ & CF table: (ca & -oll) & & \\
\hline & 0.98 & 0.98 & 0.98 & 0.98 \\
\hline & $(0.23-4.23)$ & $(0.23-4.23)$ & $(0.23-4.23)$ & $(0.23-4.25)$ \\
\hline & 9.23 & 9.16 & 9.29 & 9.36 \\
\hline & $(2.22-38.3)$ & $(2.21-38.0)$ & $(2.21-38.1)$ & $(2.21-38.5)$ \\
\hline & 7.39 & 7.39 & 7.39 & 7.39 \\
\hline $1^{s t} O I(1)$ & $(1.97-27.6)$ & $(1.97-27.6)$ & $(1.97-27.6)$ & $(1.97-27.6)$ \\
\hline & 0.8 & 0.81 & 0.81 & 0.8 \\
\hline${ }^{t} O I(0)$ & $(0.47-1.36)$ & $(0.48-1.37)$ & $(0.47-1.38)$ & $(0.46-1.38)$ \\
\hline & 9.23 & 9.16 & 9.16 & 9.24 \\
\hline $2^{\text {nd }} O I$ & $(2.22-38.3)$ & $(2.21-38.0)$ & $(2.21-38.1)$ & $(2.21-38.5)$ \\
\hline $\bar{D}$ & 1.58 & 1.6 & 1.6 & 1.58 \\
\hline $\mathbf{K}_{C}$ & $(1.04-2.39)$ & $(1.10-2.32)$ & $(1.09-2.33)$ & $(1.07-2.31)$ \\
\hline
\end{tabular}

After getting all possible combinations from admissible $C F$ tables under scenario I for cases and controls, the bias-adjusted values of Eqs. 3-11 were computed for all 8 combinations. Only 4 combinations were listed here because the results from the other 4 combinations were similar; hence it was omitted to save space (table 4). On the one hand, the bias-adjusted values for the unstratified exposure odds ratio, the Mantel-Haenezel summary odds ratios, the odds ratio for the stratum without the presence of $C$, the $1^{\text {st }}$ order interaction for controls are almost unchanged. On the other hand, the bias-adjusted values for the stratified odds ratio with the presence of $C$ and the $1^{\text {st }}$ order interaction for cases were $35 \%$ higher than the crude estimator. Similarly, the bias-adjusted value for the $2^{\text {nd }}$ order multiplicative interaction was 36\% higher than the crude estimator.

\section{Discussion}

This is a study on the effect of joint misclassification of exposure and extraneous (confounding) variables on the association among the disease, exposure and confounding variables. Through the use of counterfactual tables as a gold standard, a sensitivity analysis was conducted to examine effects on various measures used in analyzing $2 \times 2 \times 2$ tables. Both Cox \& Elwood (1991) and Walker \& Lanes (1991) also used the same data set to investigate the issue of misclassification. But, they only considered the effect of the confounder misclassification. 


\section{TZE-SAN LEE}

Some comments are appropriate to be given below:

1. Two scenarios concerning the joint misclassification were considered, that is, the classification errors of exposure and confounding variables are independent (scenario I) or not (scenario II). It turned out that results were very different for cases and controls. Under scenario I, there were 2 and 4 admissible $C F$ tables for cases and controls respectively. It was noticed that no admissible $C F$ tables exist, once the false positive or negative rates were greater than 0.02 . Under scenario II none and $4 \mathrm{CF}$ tables were available for cases and controls. Similarly, no admissible $C F$ tables exist for controls, once the false positive or negative rates were greater than 0.01 . Evidently, the existence of admissible $C F$ tables depends on the structure of their collected data for cases and controls.

2. From the result of this study, the effect of joint misclassification of the exposure and confounding variables varies. It depends on which statistics is used to measure the effect (table 4). For example, although the value of $\breve{R}_{E}$ is just a little larger than that of $\hat{R}_{E}$, it implies that the bias-adjusted estimator is significantly greater than one because its lower bound of $95 \% C I$ moves further from one than that of $\hat{R}_{E}$. Its 95\% CI becomes widened than that of $\hat{R}_{E}$, even though the values of $\breve{R}_{E \mid M H}$ are approximately the same as that of $\hat{R}_{E \mid M H}$. The values of $\breve{R}_{E \mid C=1}, \breve{R}_{1^{s} \text { OI(1) }}$ and $\breve{\phi}_{\text {hmg }}$ are much larger than that of the corresponding crude estimators $\hat{R}_{E \mid C=1}, \hat{R}_{\left.1^{t} \text { OII } 1\right)}$ and $\hat{\phi}_{h m g}$. The value of $\breve{R}_{C}$ which is greater than that of $\hat{R}_{C}$ indicates that the strength of confounding by the use of oral corticosteroids is at least 1.3 times of the group without using it. Lastly, the effect of joint misclassification of $E$ and $C$ on the measure of $R_{E \mid C=0}, R_{1^{s t} O I(0)}$, and $\phi_{E \mid C}$ is almost negligible.

3. Advantages in using counterfactual tables to conduct the sensitivity analysis are many folds. First, it solves the problem of finding a gold standard in order to calculate the misclassification probability. Second, the assumption of nondifferential misclassification is not needed on any factor under study. For example, if the exposure factor is not misclassified, all that has to be done is to keep the marginal totals for 
the exposure factor fixed in selecting counterfactual tables. Third, all results are strictly obtained from the collected data. Hence, the drawn conclusion is real data-based rather than the hypothetical data used by other authors (Greenland 1980; Greenland \& Robins 1985).

4. Although the extraneous variable $C$ (the use of corticosteroid) was not judged as a confounder by the estimated value of $\hat{\phi}_{E \mid C}=0.98$, it was shown to be a confounder by indication (Psaty et al. 1999) or by association with the death and the exposure (Miettinen 1974) or by not being equally distributed (lack of comparability) in the categories of the exposure variable (the use of prescribed fenoterol) (Miettinen 1985). Further, it was shown to be an effect modifier by the statistics of $\hat{\phi}_{h m g}$ or $\hat{R}_{2^{n d} O I}$. Once an effect modification is present, whether $C$ is a confounder becomes not an issue. Rather, stratum-specific odds ratio estimates $\left(\hat{R}_{E \mid C=i}\right)$ should be reported because summary estimates do not convey information on the pattern of variation of stratum-specific estimates. For other references on the confounder, please see Wickramaratne \& Holford (1987), Weinberg (1993), and Yiostalo \& Knuuttila (2006).

\section{Acknowledgements}

All numerical calculations were done with the use of the EXCEL spreadsheet.

\section{References}

Agresti, A. (2002). Categorical Fata Analysis. (2 ${ }^{\text {nd }}$ ed.) New York: Wiley.

Ahlbom, A. \& Steinbeck, G. (1992). Aspects of misclassification of confounding factors. American Journal Industrial Medicine, 21, 107-112.

Axelson, O. (1978). Aspects on confounding in occupational health epidemiology. (Letter). Scandinavian Journal of Work, Environment, \& Health, 4, 98-102.

Barron, B. A. (1977). The effects of misclassification on the estimation of relative risk. Biometrics, 33, 414-418. 


\section{TZE-SAN LEE}

Cox, B., \& Elwood, J. M. (1991). The effect on the stratum-specific odds ratios of nondifferential misclassification of a dichotomous covariate. American Journal of Epidemiology, 133, 202-207.

Crane, J., Pearce, N., Flatt, A., Burgess, C., Jackson, R., Kwong, T., Ball, M., \& Beasley, R. (1989). Prescribed fenterol and death from asthma in New Zealand, 1981-1983: Case-Control study. Lancet, 1, 917-922.

Epstude, K., \& Roese, N. (2008). The functional theory of counterfactual thinking. Personality And Social Psychology Review, 12(2), 168-192. doi:10.1177/1088868308316091

Fleiss, J., Levin, B., \& Paik, M.C. (2003). Statistical Methods for Rates and Proportions, $3^{\text {rd }}$ edition. John Wiley and Sons, Inc., New York.

Fung, K. Y., \& Howe, G. R. (1984). Methodological issues in case-control studies III: - The effect of joint misclassification of risk factors and confounding factors upon estimation and power. International Journal of Epidemiology, 13, 366-370.

Greenland, S. (1980). The effect of misclassification in the presence of covariates. American Journal of Epidemiology, 112, 564-569.

Greenland, S., \& Robins, J. M. (1985). Confounding and misclassification. American Journal of Epidemiology, 122, 495-506.

Gustafson, P. (2004). Measurement Error and Misclassification in Statistics and Epidemiology: Impacts and Bayesian Adjustments. Chapman \& Hall, Boca Raton, FL.

Kleinbaum, D. G., Kupper, L. L., \& Morgenstern, H. (1982). Epidemiologic Research: Principles and Quantitative Methods. John Wiley and Sons, Inc., New York.

Kupper, L. L. (1984). Effects of the use of unreliable surrogate variables on the validity of epidemiologic research studies. American Journal of Epidemiology, 120, 643-648.

Lee, T-S. (2009). Bias-adjusted exposure odds ratio for misclassified data.

The Internet Journal of Epidemiology, 6(2). Accessed from http://www.ispub.com/journal/the-internet-journal-of-epidemiology/volume-6number-2/bias-adjusted-exposure-odds-ratio-for-misclassification-data-1.html

Lee, T-S. (2013). The effect on the interaction by the joint misclassification of two exposure factors in contingency tables. A special issue on Environmental Health Statistics: Epidemiology, Toxicology and Related Issues, Journal of the Indian Society of Agricultural Statistics, 67, 1-9. 


\section{JOINTLY MISCLASSIFIED EXPOSURE \& CONFOUNDING VARIABLES}

Mantel, N., \& Haenszel, W. (1959). Statistical aspects of the analysis of data from retrospective studies of disease. Journal of the National Cancer Institute, 22, 719-748.

Miettinen, O. S. (1972). Components of the crude risk ratio. American Journal of Epidemiology, 96, 168-172.

Miettinen, O. S. (1974). Confounding and effect-modification. American Journal of Epidemiology., 100, 350-353.

Miettinen, O. S. (1985). Theoretical Epidemiology: Principles of Occurrence Research in Medicine. New York: Wiley.

O’Donnell, T. V., Rea, H. H., Holst, \& Sears, M. R. (1989). Fenoterol and fatal asthma. The Lancet, 1, 1070-1071.

Psaty, B. M., Koepsell, T. D., Lin, D., Weiss, N. S., Siscovick, D. S., Rosendaal, F. R., Pahor, M., \& Furberg, C. D. (1999). Assessment and control for confounding by indication in observational studies. Journal of the American Geriatrics Society, 47, 749-754.

Rothman, K. J., Greenland, S., \& Lash, T. L. (2008). Modern Epidemiology, $3^{\text {rd }}$ edition. Philadelphia, PA: Lippincott Williams \& Wilkins.

Savitz, D. A., \& Baron, A. E. (1989). Estimating and correcting for confounder misclassification. American Journal of Epidemiology, 129, 1062-1071.

Tzonou, A., Kaldor, J., Smith, P.G., Day, N.E., \& Trichopoulos, D. (1986). Misclassification in case-control studies with two dichotomous risk factors. Rev d'Epidém et de Santé Publ, 34, 10-17.

Walker, A. M. (1985). Misclassified confounders. American Journal of Epidemiology., 122, 921-922

Walker, A. M., \& Lanes, S. F. (1991). Misclassification of covariates. Statistics in Medicine., 10, 1181-1196.

Weinberg, C. R. (1993). Toward a clearer definition of confounding. American Journal of Epidemiology, 137, 1-8.

Wickramaratne, P. J. \& Holford, T. R. (1987). Confounding in epidemiologic studies: The adequacy of the control group as a measure of confounding. Biometrics, 43, 751-765.

Yiostalo, P. V. \& Knuuttila, M. L. (2006). Confounding and effect modification: possible explanation for variation in the results on the association between oral and systemic diseases. Journal of Clinical Periodontology, 33, 104108. 


\section{TZE-SAN LEE}

\section{Appendix A}

By adapting the variance formula obtained in Lee (2013), the variance formula is readily given for the crude and bias-adjusted estimators for the $1^{\text {st }}$ order (multiplicative) interaction as follows:

$$
\operatorname{Var}\left(\ln \left(\hat{R}_{1^{t t} \mathrm{OI}(i)}\right)\right)=n_{(i)}^{-1} \cdot a_{(i)}^{T} \Sigma_{(i)} a_{(i)}
$$

where $a_{(i)}=\left(p_{i 11}^{-1},-p_{i 10}^{-1},-p_{i 01}^{-1}, p_{i 00}^{-1}\right)^{T}$.

$$
\operatorname{Var}\left(\ln \left(\breve{R}_{1^{t t} \mathrm{OI}(i)}\right)=n_{(i)}^{-1} \cdot \dot{a}_{(i)}^{T} \Sigma_{(i)} \dot{a}_{(i)}\right.
$$

where $\dot{a}_{(i)}=\left(v_{11(\cdot ; i)} \hat{p}_{i 11},-v_{22(. ; i)} \hat{p}_{i 10},-v_{33(. ; i)} \hat{p}_{i 01}, v_{44(. ; i)} \hat{p}_{i 00}\right)^{T}, \quad\left\{\mathrm{v}_{\mathrm{jj}(. ; \mathrm{i})}\right\}$ are the $\mathrm{j}^{\text {th }}$ diagonal entry of the inverse matrix $V_{.(i)}=W_{.(i)}^{-1}, W_{.(i)}=W_{I(i)}$ or $W_{I I(i)}$, $\hat{p}_{(i)}=V_{.(i)} p_{(i)}$, and $\Sigma_{(i)}$ is given by Eq. 2 .

The variance formula is also readily given for the crude and bias-adjusted estimators for the $2^{\text {nd }}$ order (multiplicative) interaction as follows:

$$
\begin{aligned}
& \operatorname{Var}\left(\ln \left(\hat{R}_{2^{\text {nd }} \text { OI }}\right)\right)=\sum_{i=0}^{1} \operatorname{Var}\left(\ln \left(\hat{R}_{1^{s t} \text { OI }(i)}\right)\right) \\
& \operatorname{Var}\left(\ln \left(\breve{R}_{2^{n d} \text { OI }}\right)\right)=\sum_{i=0}^{1} \operatorname{Var}\left(\ln \left(\breve{R}_{1^{s t} \text { OI (i) }}\right)\right)
\end{aligned}
$$

Similarly, obtain the variance for the crude and bias-adjusted odds ratio ignoring the confounding factor $\mathrm{C}$ to be given respectively by using the delta method which is given by Eq. 14.4 in Agresti (2002):

$$
\operatorname{Var}\left(\ln \left(\hat{R}_{E}\right)\right)=\sum_{i=0}^{1} n_{(i)}^{-1} \cdot b_{(i)}^{T} \Sigma_{(i)} b_{(i)}
$$

where $b_{(1)}=\left(p_{11+}^{-1}, p_{11_{+}}^{-1},-p_{10+}^{-1},-p_{10+}^{-1}\right)^{T}$, and $b_{(0)}=\left(-p_{01+}^{-1},-p_{01+}^{-1}, p_{00+}^{-1}, p_{00+}^{-1}\right)^{T}$.

The variance of $\ln \left(\breve{R}_{E}\right)$ is given by

$$
\operatorname{Var}\left(\ln \left(\breve{R}_{E}\right)\right)=\sum_{i=0}^{1} n_{(i)}^{-1} \dot{b}_{(i)}^{T} \Sigma_{(i)} \dot{b}_{(i)}
$$




\section{JOINTLY MISCLASSIFIED EXPOSURE \& CONFOUNDING VARIABLES}

where

$$
\dot{b}_{(1)}=\left(v_{11(; 1)} \hat{p}_{11+}^{-1}, v_{22(; ;)} \hat{p}_{11+}^{-1},-v_{33(; ;)} \hat{p}_{10+}^{-1},-v_{44(; ;)} \hat{p}_{10+}^{-1}\right)^{T}
$$

$\dot{b}_{(0)}=\left(-v_{11(; 0)} \hat{p}_{01+}^{-1},-v_{22(; 0)} \hat{p}_{01+}^{-1}, v_{33(; ; 0)} \hat{p}_{00+}^{-1}, v_{44(; 0)} \hat{p}_{00+}^{-1}\right)^{T}$, and $\hat{p}_{(i)}$ is defined in Eq. A2.

The variances of the crude and bias-adjusted odds ratio stratified by the confounder $C$ are given respectively by

$$
\operatorname{Var}\left(\ln \left(\hat{R}_{E \mid C=1}\right)\right)=\sum_{i=0}^{1} n_{(i)}^{-1} \cdot c_{i \mid C=1} \Sigma_{(i)} C_{(i) \mid C=1}^{T}
$$

where $c_{(i) \mid C=1}=\left(p_{i 11}^{-1}, 0,-p_{i 01}^{-1}, 0\right)^{T}$, and $c_{(i) \mid C=0}=\left(0,-p_{i 10}^{-1}, 0, p_{i 00}^{-1}\right)^{T}$.

$$
\operatorname{Var}\left(\ln \left(\breve{R}_{E \mid C=1}\right)\right)=\sum_{i=0}^{1} n_{(i)}^{-1} \dot{C}_{(i) \mid C=1}^{T} \Sigma_{(i)} \dot{c}_{(i) \mid C=1}
$$

where

$$
\dot{C}_{(i) C=1}=\left(v_{11(; i)} \hat{p}_{i 11}^{-1}, 0,-v_{33(; i)} \hat{p}_{i 01}^{-1}, 0\right)^{T}
$$

and $\dot{C}_{(i) \mid C=0}=\left(0,-v_{22(., i)} \hat{p}_{i 10}^{-1}, 0, v_{44(\cdot, i)} \hat{p}_{i 00}^{-1}\right)^{T}$.

The variance of the crude Mantel-Haenszel summary odds ratio is given by

$$
\operatorname{Var}\left(\ln \left(\hat{R}_{E \mid M H}\right)\right)=\sum_{i=0}^{1} n_{(i)}^{-1} \cdot d_{(i)}^{T} \Sigma_{(i)} d_{(i)}
$$

where $d_{(i)}=\left(d_{1(i)}, d_{2(i)}, d_{3(i)}, d_{4(i)}\right)^{T}$ and each component in $\mathrm{d}_{(\mathrm{i})}$ is given by

$$
\begin{aligned}
& d_{1(i=1)}=\left(p_{++0} / p_{++1}\right)\left[\rho_{1} p_{001}\left(p_{101}+p_{011}+p_{001}\right)+\rho_{0} p_{101} p_{011}\right], \\
& d_{2(i=1)}=\left(p_{++1} / p_{++0}\right)\left[\rho_{1} p_{000}\left(p_{100}+p_{010}+p_{000}\right)+\rho_{0} p_{100} p_{010}\right], \\
& d_{3(i=1)}=-\left(p_{++0} / p_{++1}\right)\left[\rho_{1} p_{111} p_{001}+\rho_{0} p_{011}\left(p_{111}+p_{011}+p_{001}\right)\right], \\
& d_{4(i=1)}=-\left(p_{++1} / p_{++0}\right)\left[\rho_{1} p_{110} p_{000}+\rho_{0} p_{010}\left(p_{110}+p_{010}+p_{000}\right)\right], \\
& d_{1(i=0)}=-\left(p_{++0} / p_{++1}\right)\left[\rho_{1} p_{111} p_{001}+\rho_{0} p_{101}\left(p_{111}+p_{101}+p_{001}\right)\right], \\
& d_{2(i=0)}=-\left(p_{++1} / p_{++0}\right)\left[\rho_{1} p_{110} p_{000}+\rho_{0} p_{100}\left(p_{110}+p_{100}+p_{000}\right)\right], \\
& d_{3(i=0)}=\left(p_{++0} / p_{++1}\right)\left[\rho_{1} p_{111}\left(p_{111}+p_{101}+p_{001}\right)+\rho_{0} p_{101} p_{011}\right], \\
& d_{4(i=0)}=\left(p_{++1} / p_{++0}\right)\left[\rho_{1} p_{110}\left(p_{110}+p_{100}+p_{010}\right)+\rho_{0} p_{100} p_{010}\right],
\end{aligned}
$$




\section{TZE-SAN LEE}

$$
\begin{aligned}
& \rho_{1} \equiv\left(p_{++0} p_{111} p_{001}+p_{++1} p_{110} p_{000}\right)^{-1}, \\
& \rho_{0} \equiv\left(p_{++0} p_{101} p_{011}+p_{++1} p_{100} p_{010}\right)^{-1}
\end{aligned}
$$

The variance for the BACP of the Mantel-Haenszel summary odds ratio is given by

$$
\operatorname{Var}\left(\ln \left(\breve{R}_{E \mid M H}\right)\right)=\sum_{i=0}^{1} n_{(i)}^{-1} \cdot \dot{d}_{(i)} \Sigma_{(i)} \dot{d}_{(i)}^{T}
$$

where $\dot{d}_{(i)}=\left[\dot{d}_{1(i)}, \dot{d}_{2(i)}, \dot{d}_{3(i)}, \dot{d}_{4(i)}\right]^{T}$ and each component in $\dot{d}_{(i)}$ is given by

$$
\begin{aligned}
& \dot{d}_{1(i=1)}=v_{11(: ;)}\left(\hat{p}_{++0} / \widehat{p}_{++1}\right)\left[\dot{\rho}_{1} \widehat{p}_{001}\left(\widehat{p}_{101}+\widehat{p}_{011}+\widehat{p}_{001}\right)+\dot{\rho}_{0} \widehat{p}_{101} \hat{p}_{011}\right] \text {, } \\
& \dot{d}_{2(i=1)}=v_{22(: ;)}\left(\hat{p}_{++1} / \hat{p}_{++0}\right)\left[\dot{\rho}_{1} \hat{p}_{000}\left(\hat{p}_{100}+\hat{p}_{010}+\hat{p}_{000}\right)+\dot{\rho}_{0} \hat{p}_{100} \hat{p}_{010}\right] \text {, } \\
& \dot{d}_{3(i=1)}=-v_{33(: ;)}\left(\hat{p}_{++0} / \hat{p}_{++1}\right)\left[\dot{\rho}_{1} \widehat{p}_{111} \hat{p}_{001}+\dot{\rho}_{0} \widehat{p}_{011}\left(\hat{p}_{111}+\widehat{p}_{011}+\widehat{p}_{001}\right)\right] \text {, } \\
& \dot{d}_{4(i=1)}=-v_{44(: ;)}\left(\hat{p}_{++1} / \hat{p}_{++0}\right)\left[\dot{\rho}_{1} \hat{p}_{110} \hat{p}_{000}+\dot{\rho}_{0} \widehat{p}_{010}\left(\widehat{p}_{110}+\widehat{p}_{010}+\widehat{p}_{000}\right)\right] \text {, } \\
& \dot{d}_{1(i=0)}=-v_{11(; ; 0)}\left(\hat{p}_{++0} / \hat{p}_{++1}\right)\left[\dot{\rho}_{1} \hat{p}_{111} \hat{p}_{001}+\dot{\rho}_{0} \widehat{p}_{101}\left(\hat{p}_{111}+\widehat{p}_{101}+\widehat{p}_{001}\right)\right] \text {, } \\
& \dot{d}_{2(i=0)}=-v_{22(: ; 0)}\left(\hat{p}_{++1} / \hat{p}_{++0}\right)\left[\dot{\rho}_{1} \hat{p}_{110} \hat{p}_{000}+\dot{\rho}_{0} \widehat{p}_{100}\left(\widehat{p}_{110}+\widehat{p}_{100}+\widehat{p}_{000}\right)\right] \text {, } \\
& \dot{d}_{3(i=0)}=v_{33(; ; 0)}\left(\hat{p}_{++0} / \hat{p}_{++1}\right)\left[\dot{\rho}_{1} \hat{p}_{111}\left(\widehat{p}_{111}+\widehat{p}_{101}+\widehat{p}_{001}\right)+\dot{\rho}_{0} \widehat{p}_{101} \hat{p}_{011}\right] \text {, } \\
& \dot{d}_{4(i=0)}=v_{44(: ; 0)}\left(\hat{p}_{++1} / \hat{p}_{++0}\right)\left[\dot{\rho}_{1} \hat{p}_{110}\left(\hat{p}_{110}+\widehat{p}_{100}+\widehat{p}_{010}\right)+\dot{\rho}_{0} \widehat{p}_{100} \hat{p}_{010}\right] \text {, } \\
& \dot{\rho}_{1} \equiv\left(\widehat{p}_{++0} \hat{p}_{111} \hat{p}_{001}+\hat{p}_{++1} \hat{p}_{110} \hat{p}_{000}\right)^{-1} \text {, } \\
& \dot{\rho}_{0} \equiv\left(\widehat{p}_{++0} \hat{p}_{101} \hat{p}_{011}+\widehat{p}_{++1} \hat{p}_{100} \hat{p}_{010}\right)^{-1} \text {. }
\end{aligned}
$$

The variance of $\ln \left(\hat{R}_{C}\right)$ is given by

$$
\operatorname{Var}\left(\ln \left(\hat{R}_{C}\right)\right)=\sum_{i=0}^{1} n_{(i)}^{-1} \cdot e_{(i)}^{T} \Sigma_{(i)} e_{(i)}
$$

where each component of the vector $e_{(i)}=\left(e_{1(i)}, e_{2(i)}, e_{3(i)}, e_{4(i)}\right)^{T}$ is given by

$$
\begin{aligned}
& e_{1(1)}=0 \quad, \quad e_{2(1)}=\rho p_{101} p_{000}, \quad e_{3(1)}=\rho p_{10+}^{-1} p_{100}\left(p_{110} p_{000}-p_{010} p_{001}\right), \\
& e_{4(1)}=\rho p_{10+}^{-1} p_{100}^{-1}\left(p_{110} p_{000} p_{101}^{2}-p_{010} p_{001} p_{100}^{2}\right), \quad e_{1(0)}=-p_{01+}^{-1}, \\
& e_{2(0)}=\rho p_{01+}^{-1}\left(p_{100} p_{001} p_{011}-p_{000} p_{110} p_{101}\right) \\
& e_{3(0)}=\rho\left[p_{000}\left(p_{110} p_{101}+p_{100} p_{010}\right)+2 p_{100} p_{010} p_{001}\right],
\end{aligned},
$$




\section{JOINTLY MISCLASSIFIED EXPOSURE \& CONFOUNDING VARIABLES}

$e_{4(0)}=\rho p_{00+}^{-1} p_{000} p_{001}\left(p_{110} p_{000}^{2}-p_{100} p_{010} p_{001}\right) ; \rho=\left(p_{000} p_{110} p_{101}+p_{100} p_{010} p_{001}\right)^{-1}$.

The variance of $\ln \left(\breve{R}_{C}\right)$ is given by

$$
\operatorname{Var}\left(\ln \left(\breve{R}_{C}\right)\right)=\sum_{i=0}^{1} n_{(i)}^{-1} \cdot \dot{e}_{(i)}^{T} \Sigma_{(i)} \dot{e}_{(i)}
$$

where each component of the vector $\dot{e}_{(i)}=\left(\dot{e}_{1(i)}, \dot{e}_{2(i)}, \dot{e}_{3(i)}, \dot{e}_{4(i)}\right)^{T}$ is given by

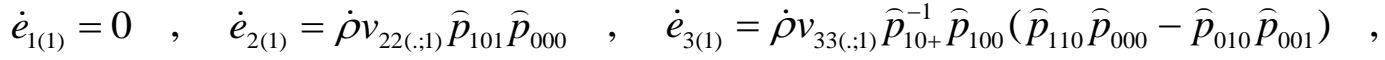

$$
\begin{aligned}
& \dot{e}_{4(1)}=-\dot{\rho} \hat{p}_{10+}^{-1} \hat{p}_{100}^{-1}\left(\widehat{p}_{110} \hat{p}_{000} \hat{p}_{101}^{2}+\widehat{p}_{010} \hat{p}_{001} \hat{p}_{100}^{2}+2 \widehat{p}_{110} \hat{p}_{101} \hat{p}_{100} \hat{p}_{000}\right) ; \\
& \dot{e}_{1(0)}=-v_{11(: ; 0)} \hat{p}_{01+}^{-1} \quad, \quad \dot{e}_{2(0)}=\dot{\rho} v_{22(: ; 0)} \hat{p}_{01+}^{-1}\left(\widehat{p}_{100} \widehat{p}_{011} \hat{p}_{001}-\widehat{p}_{000} \hat{p}_{110} \hat{p}_{101}\right) \quad ， \\
& \dot{e}_{3(0)}=\dot{\rho} v_{33(\cdot ; 0)} \hat{p}_{00+}^{-1}\left[\hat{p}_{000}\left(\widehat{p}_{110} \hat{p}_{101}+\widehat{p}_{100} \hat{p}_{010}\right)+2 \widehat{p}_{100} \widehat{p}_{010} \hat{p}_{001}\right] \text {, } \\
& \dot{e}_{4(0)}=\dot{\rho} v_{44(: ; 0)} \hat{p}_{00+}^{-1} \hat{p}_{000}^{-1}\left(\hat{p}_{110} \hat{p}_{101} \hat{p}_{000}^{2}-\hat{p}_{100} \hat{p}_{010} \hat{p}_{001}^{2}\right) \\
& \dot{\rho} \equiv\left(\widehat{p}_{000} \hat{p}_{110} \hat{p}_{101}+\widehat{p}_{100} \hat{p}_{010} \hat{p}_{001}\right)^{-1} \text {. }
\end{aligned}
$$

Lastly, the variances of the crude and bias-adjusted estimators for Eqs. 7 \& 8 are given respectively by

$$
\begin{aligned}
& \operatorname{Var}\left(\ln \left(\hat{\phi}_{E \mid C}\right)\right) \approx \operatorname{Var}\left(\ln \left(\hat{R}_{E \mid M H}\right)+\operatorname{Var}\left(\ln \left(\hat{R}_{E}\right)\right),\right. \\
& \operatorname{Var}\left(\ln \left(\breve{\phi}_{E \mid C}\right)\right) \approx \operatorname{Var}\left(\ln \left(\breve{R}_{E \mid M H}\right)+\operatorname{Var}\left(\ln \left(\breve{R}_{E}\right)\right),\right. \\
& \operatorname{Var}\left(\ln \left(\hat{\phi}_{h m g}\right)\right)=\operatorname{Var}\left(\ln \left(\hat{R}_{E \mid C=1}\right)+\operatorname{Var}\left(\ln \left(\hat{R}_{E \mid C=0}\right)\right),\right. \\
& \operatorname{Var}\left(\ln \left(\breve{\phi}_{h m g}\right)\right)=\operatorname{Var}\left(\ln \left(\breve{R}_{E \mid C=1}\right)+\operatorname{Var}\left(\ln \left(\breve{R}_{E \mid C=0}\right)\right) .\right.
\end{aligned}
$$

